Int. J. Morphol.,

33(3):835-841, 2015.

\title{
Efecto de la Vitrificación de Ovocitos Humanos sobre la Capacidad de Unión y el Estado Acrosomal de Espermatozoides Humanos
}

\author{
Effect of the Vitrification of Human Oocytes on the Binding \\ Capacity and Acrosome Status of Human Sperm
}

\author{
Ismael Vilella"; Eva Ma García****; Jorge Ten**; Rafael Bernabeu**; \\ Yolanda Segovia Huerta*; María José Gómez-Torres ${ }^{*, * * * *}$
}

VILELLA, I.; GARCÍA, E. M.; TEN, J.; BERNABEU, R.; SEGOVIA, H. Y.; GÓMEZ-TORRES, M. J. Efecto de la vitrificación de ovocitos humanos sobre la capacidad de unión y el estado acrosomal de espermatozoides humanos. Int. J. Morphol., 33(3):835-841, 2015.

RESUMEN: Conocer los aspectos moleculares que acontecen en el proceso de unión de los espermatozoides humanos a la zona pelúcida (ZP) humana es uno de los grandes retos de la biología de la Reproducción. Por otra parte conocer si el proceso de fecundación puede verse afectado por la criopreservación de los gametos femeninos sigue siendo otra cuestión debatida en la literatura. En base a esto, el objetivo principal de este trabajo fue conocer si la vitrificación ovocitaria puede alterar la interacción de los espermatozoides con el glicocáliz de la ZP y demostrar si la ZP de estos ovocitos pierde la capacidad de inducir la reacción acrosómica en los espermatozoides. Según nuestros resultados el método de vitrificación ovocitaria cerrado (S3) no altera la capacidad de unión de los espermatozoides a la zona pelúcida, ni la capacidad de ésta para inducir la reacción acrosómica.

PALABRAS CLAVE: Test Hemizona; Ovocitos Humanos; Reacción Acrosómica; Vitrificación y Espermatozoides Humanos.

\section{INTRODUCCIÓN}

La infertilidad es una enfermedad que afecta a un 10$15 \%$ de las parejas en edad reproductiva. De estas, un $30 \%$ se debe a causa femenina, otro $30 \%$ a causa masculina y un $40 \%$ a causas mixtas. Pensamos que es necesario desarrollar nuevos biomarcadores a nivel de los gametos y embriones que nos permitan mejorar las Técnicas de Reproducción Asistida (TRA).

Otro aspecto importante en el campo de la reproducción es la criopreservación de gametos. Es una práctica habitual y cada vez más demandada en las clínicas de reproducción asistida. La literatura es controvertida en cuanto a la viabilidad, posibles daños celulares y pérdida de capacidad fecundante de los gametos femeninos tras ser sometidos a la vitrificación (Boiso, 2001).

En el presente trabajo intentamos estudiar algunos aspectos moleculares que acontecen en el proceso de unión de los espermatozoides humanos a la zona pelúcida humana. Es de vital importancia el conocimiento de los mecanismos y las bases moleculares implicadas en la interacción espermatozoide-ovocito ya que podría posibilitar el desarrollo de nuevas pruebas para diagnosticar las causas moleculares de la fertilidad o terapias para el tratamiento de enfermedades específicas, mejoras en la calidad de los embriones producidos in vitro, desarrollo de vacunas anticonceptivas, etc. Además podremos ver sí estos mecanismos de unión pueden verse alterados por el mecanismo de vitrificación.

Existen tres niveles en la interacción espermatozoideovocito: la zona pelúcida (ZP), la membrana plasmática y el citoplasma.

El primer paso es la unión espermatozoide-ZP, no es completamente específica de especie, presenta algunas restricciones (Rankin \& Dean, 2000). El espermatozoide tras unirse a la ZP sufre la RA para atravesarla (Yanagimachi, 1994). Se dice que la unión del espermatozoide a la ZP es un proceso mediado por glicoproteínas (Nixon et al., 2001), pero los oligosacáridos precisos a los que se une el esper-

* Departamento de Biotecnología, Facultad de Ciencias, Universidad de Alicante, Alicante, España.

${ }^{* *}$ Instituto Bernabeu de Fertilidad y Ginecología de Alicante, Alicante, España.

Este trabajo fue subvencionado por el Vicerrectorado de Investigación de la Universidad de Alicante (VIGROB-137). 
matozoide permanecen bajo debate y pueden variar dependiendo de la especie.

En mamíferos la ZP aparece como la estructura implicada en la unión del espermatozoide e inducción de la reacción acrosómica. Además algunas de sus funciones in vivo es prevenir la polispermia mediante mecanismos que provocan el endurecimiento de la ZP, la proteólisis y la eliminación de receptores para la unión de espermatozoides (Lindsay \& Hedrick, 2004).

En cuanto a la ZP, existe un alto grado de homología entre especies para la secuencia de aminoácidos de la ZP3. La ZP3 es una proteína que se considera responsable de la unión del espermatozoide en diferentes especies. En el hombre y el cerdo la homología a nivel de ZP3 se cifra en el 78,9 $\%$ (Zhu \& Naz, 1999). Sabiendo esto, se plantea estudiar si es posible la unión del espermatozoide humano a la ZP porcina, que sería de gran utilidad para el estudio de la funcionalidad espermática humana. El estudio de la interacción espermatozoide-ZP entre gametos humanos, presenta limitaciones debido a la dificultad para obtener ZP humana. Por esta razón numerosos grupos de investigación han intentado obtener ZP humana recombinante utilizando células $\mathrm{CHO}$ (cells hamster ovary), las cuales en algunos casos se ha demostrado que son funcionales (Bray et al., 2002), mientras que en otros la proteína no posee la actividad biológica esperada (Martic et al., 2004). Se han publicado los resultados obtenidos utilizando péptidos de ZP humana recombinante que inducen la RA (Ni et al., 2006). De cualquier modo su uso no se ha extendido a nivel clínico, por lo que sigue siendo de interés buscar nuevas alternativas al uso de la ZP humana. Para ello se ha modificado el Test de hemizona, y hemos desarrollado un Bioensayo utilizando zonas pelúcidas (ZP) completas, procedentes de ovocitos no fecundados en los que se extrae el citoplasma.

El objetivo de este trabajo fue evaluar el efecto que tiene la vitrificación de los ovocitos, sobre la capacidad de unión de los espermatozoides a la ZP. Para ello se evaluó el patrón de unión y distribución de los espermatozoides a la ZP mediante Microscopia Electrónica de Barrido (MEB) y el estado acrosomal mediante microscopia de fluorescencia.

\section{MATERIAL Y MÉTODO}

Material Biológico. Se utilizaron 5 muestras de semen procedentes de varones sanos previo consentimiento. Se realizó un seminograma clásico determinando los parámetros de concentración y motilidad siguiendo los criterios de la OMS (WHO, 2010). Se emplearon 44 ovocitos no fecundados que procedían mujeres inducidas en el programa de reproducción asistida del Instituto Bernabeu de Fertilidad y Ginecología de Alicante. Todas ellas firmaron el consentimiento informado.

Bioensayo "Test de Unión Espermática a la Zona Pelúcida" (TUEZP). Una de las inconvenientes que tenemos para realizar el test con ZP es la limitación de material y las condiciones de viabilidad. Los grupos de trabajo se establecieron en función del modo en el que fueron conservadas las ZPs. Grupo ZP S.S: En dicho grupo las ZPs fueron conservadas en Solución Salina (SS) hipertónica que contiene cloruro de magnesio hexahidratado $1,5 \mathrm{M}$, polivinil pirrolidona (PVP) al 0,1\% y tampón HEPES-Sodio $40 \mathrm{mM}$; en la que los ovocitos dejan de ser viables en esta solución, sin embargo la ZP permanece intacta. Grupo ZP VIT: En este grupo los ovocitos se criopreservaron mediante vitrificación, que es un método de criopreservación rápido en el que el material se solidifica a muy bajas temperaturas $\left(-196^{\circ} \mathrm{C}\right)$ en ausencia de cristales de hielo. En este caso nosotros empleamos un método de vitrificación cerrado llamado S3 (Stachecki, 2009).

Obtención de zonas. Se tiene que romper el ovocito, liberando el citoplasma al exterior y quedando únicamente la ZP; mediante pipetas Pasteur de un diámetro determinado muy fino, el cual debe ser del diámetro justo para cuando se aspiren los ovocitos estos lo hagan con mucha dificultad y se rompan al devolverlos al medio.

Preparación del semen. Los espermatozoides móviles fueron seleccionados por el método de "swim-up". Hacemos placas de incubación con gotas de $40 \mathrm{ml}$ de dicho semen para tener una concentración aproximada por gota de $5 \times 10^{5}$ espermatozoides. En cada una de las gotas se van depositando las ZP.

Incubación. Las gotas se sumergieron en aceite mineral de Sigma y la placa se depositó en la incubadora a $37^{\circ} \mathrm{C}$ y $5 \%$ $\mathrm{CO}_{2}$ durante dos tiempos diferentes $\mathrm{t} 1=1 \mathrm{~h} \mathrm{y} \mathrm{t} 2=3 \mathrm{~h}$. Transcurrido este tiempo se valoró la incubación mediante microscopia óptica de campo claro y se obtuvo el complejo formado por la ZP con los espermatozoides unidos a la zona.

Separación de los espermatozoides unidos. Los complejos se pasaron por 3 gotas de G-MOPS de Vitrolife para eliminar espermatozoides que no se habían unido y que pudieran interferir. Después se pasó el complejo a un portaobjetos grande (diámetro $18 \mathrm{~mm}$ ) donde con una pipeta de diámetro estrecho se separan los espermatozoides unidos a la ZP, desechando la ZP y quedándonos con los espermatozoides que se habían unido durante los tiempos de incubación. En estas células se valoró el estado acrosomal 
(Liu \& Baker, 1996), mediante la técnica que a continuación detallaremos. Además en la placa donde tenemos las gotas con los complejos ZP-espermatozoides hay una gota de incubación donde el complejo allí presente no se separan los espermatozoides unidos a la ZP sino que se quiere valorar el complejo allí formado en el MEB.

Pruebas control. El grupo control 1 fueron los espermatozoides no unidos a la ZP de la gota de incubación. El grupo control 2 fueron los espermatozoides capacitados incubados a ambos tiempos que no estuvieron en contacto con la ZP. Posteriormente se procesaron las muestras para su posterior estudio.

Microscopía electrónica de barrido (MEB). Mediante MEB se valoró el número de espermatozoides adheridos a las ZP y los distintos patrones de distribución de los espermatozoides, solamente para el tiempo de incubación de 3 h. Para evaluar los patrones de distribución se dividió la ZP en cuatro cuadrantes en el sentido de la agujas del reloj y se contaron los espermatozoides de cada cuadrante con ayuda del Adobe Photoshop CS3. Los complejos se orientaron de forma que para todos los casos, el cuadrante A fue el que menos número de espermatozoides adheridos contuvo.

También se valoró si existían diferencias significativas en los patrones de distribución al usar ZP procedentes de ovocitos en solución salina hipertónica o vitrificados.

Microscopía óptica (MO). Este microscopio nos proporcionó una visión rápida y panorámica de cada caso. Lo que hicimos fue valorar los complejos ZP-espermatozoides con un microscopio óptico Nikon Eclipse TE200 (Fig. 1).

Valoración de la Reacción acrosómica. Para el estudio del estado del acrosoma se empleó una lectina Pisum sativum conjugada con el fluorocromo FITC (PSA-FITC). Esta lectina permite reconocer terminales manosa, glucosa y glucosamina (Goldstein \& Portez, 1986) de glicoconjugados localizados en la matriz acrosomal, por lo que asociada a una fluoresceína puede identificar espermatozoides con el acrosoma intacto y diferenciarlos de aquellos que sí han sufrido la reacción acrosómica. Es por lo tanto una tinción negativa, en la que el espermatozoide no fluorescente se considera como reaccionado $(\mathrm{RA}+)$, mientras que un espermatozoide con acrosoma intacto se ve el marcaje fluorescente en la parte anterior de la cabeza (RA-) (Fig. 2) (Kawamoto et al., 1999). El microscopio de fluorescencia empleado fue Leica DMRB.

Análisis estadístico. Se utilizó el paquete estadístico SPSS versión 12.0 (SPSS Inc., Illinois, USA). Se utilizo la prueba Kolmogorov-Smirnov. Se tomo como intervalo de confian- za el 95\%, es decir, se rechazaba la hipótesis nula de ajuste a una distribución normal cuando el nivel crítico de significación (p) asociado al estadístico $\mathrm{Z}$ de la prueba era menor que $0,05(\mathrm{p}<0,05)$. Las variables que no se ajustaban a una distribución normal se les realiza una transformación logarítmica, y se volvió a comprobar su ajuste $(\mathrm{p}<0,05)$.

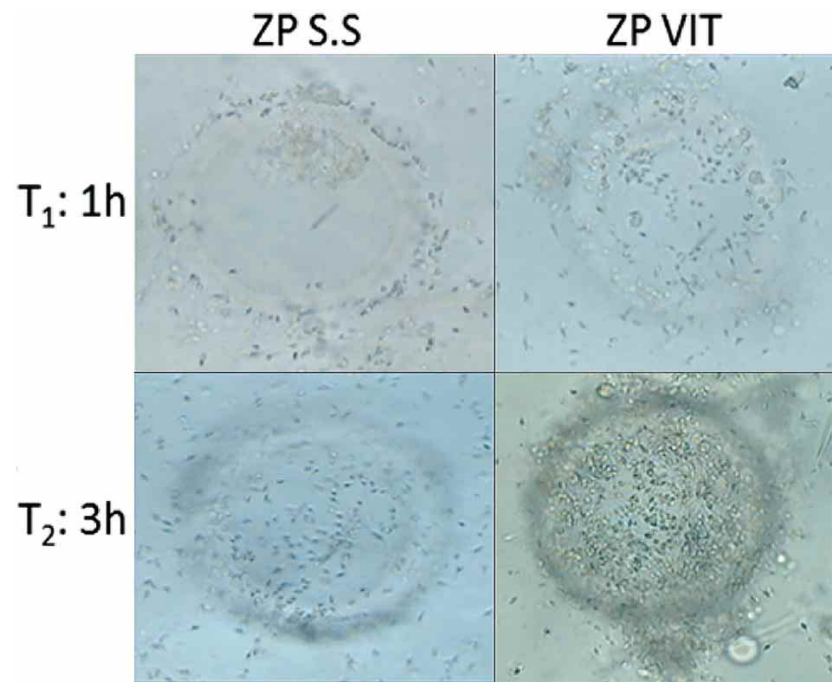

Fig. 1. Imágenes de microscopia óptica en los grupos de estudio para los diferentes tiempos de incubación 1 h y 3 h, x40. ZP S.S: Zonas Pelúcidas en Solución Salina; ZP VIT: Zonas Pelúcidas Vitrificadas.

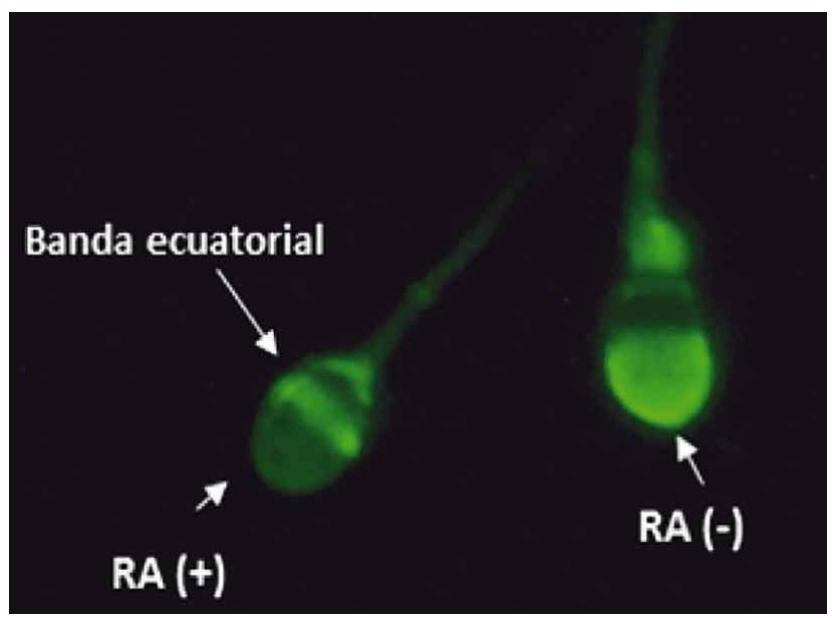

Fig. 2. Microfotografía de fluorescencia que ilustra espermatozoide con reacción acrosómica (RA+) y espermatozoide no reaccionado (RA-), 63x.

\section{RESULTADOS}

Patrón de distribución de los espermatozoides adheridos a la ZP mediante: microscopia óptica (MO) y microscopia electrónica de barrido (MEB). Como se pue- 
VILELLA, I.; GARCÍA, E. M.; TEN, J.; BERNABEU, R.; SEGOVIA, H. Y.; GÓMEZ-TORRES, M. J. Efecto de la vitrificación de ovocitos humanos sobre la capacidad de unión y el estado acrosomal de espermatozoides humanos. Int. J. Morphol., 33(3):835-841, 2015.

de ver en la Figura 3, a nivel cualitativo existen ciertas diferencias, en el número de espermatozoides adheridos a la ZP al utilizar ZP que se habían conservado en solución salina (ZP S.S), frente a aquellas que procedían de ovocitos vitrificados (ZP VIT), en este último grupo es mayor en número de espermatozoides.

Tanto en la Figura 3 como en la Figura 4 se puede observar como hay una diferencia visible en el número de espermatozoides unidos entre los cuadrantes C y D y los cuadrantes A y B; pues suele ser mayor en C y D que en el resto. Aunque no se encontraron diferencias significativas.

Valoración de espermatozoides adheridos mediante microscopia de fluorescencia. Como ya se explicó anteriormente los espermatozoides adheridos a la ZP, fueron separados de esta para su posterior valoración de la RA, pero además dichas células fueron marcadas con DAPI, para visualizar el núcleo de cada espermatozoide y poder contar el número total de espermatozoides unidos a las ZP mediante el microscopio de fluorescencia.

Esta información fue complementaria a la que nos aportaban el MO y el MEB, sobre el número de espermatozoides que tenían adheridos las ZP S.S y las ZP vitrificadas.

\section{Valoración del número de espermatozoides unidos a ZP mediante DAPI.}

a) Efecto del tiempo para las ZP vitrificadas: Como podemos observar en el Figura 5, no existen diferencias significativas en el número de espermatozoides adheridos, en función del tiempo de incubación. Sí que se observa un aumento en el número de espermatozoides adheridos a las 3 horas. Pues también destacar que a las 3 horas de incubación obtuvimos una mayor dispersión de los casos.
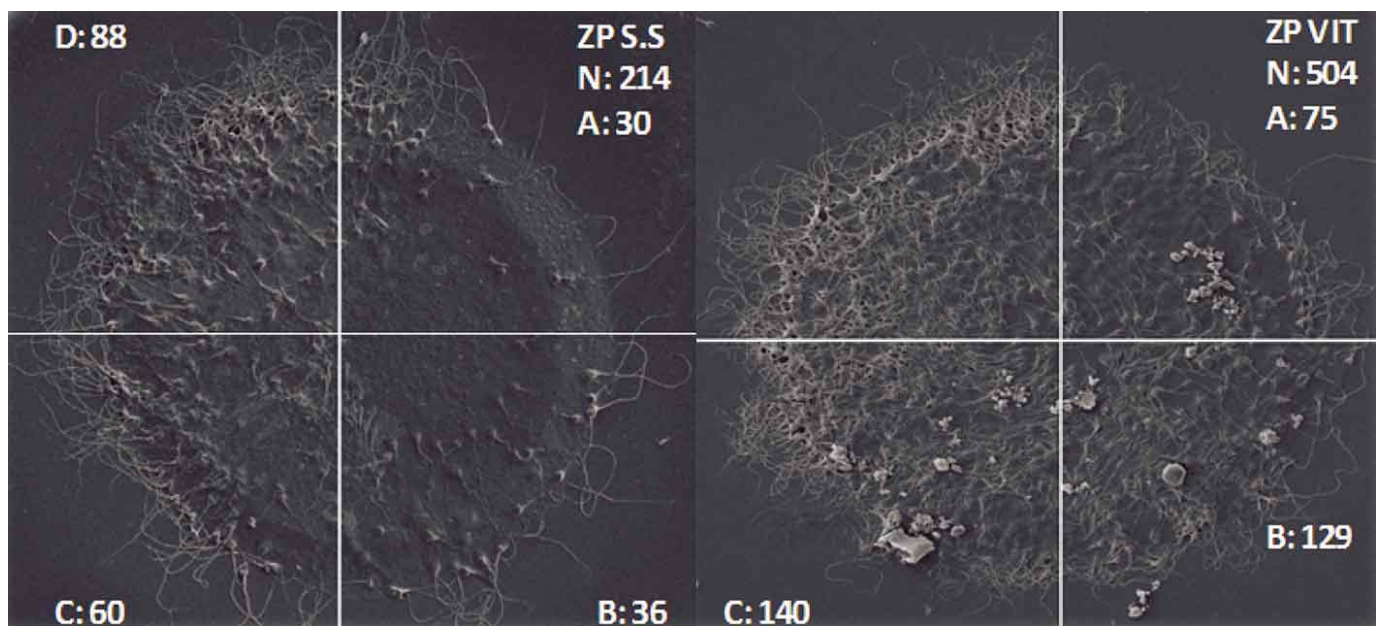

Fig. 3. Microfotografías del MEB de dos complejos ZP-espermatozoides donde se han divido los cuadrantes y se han contados los espermatozoides adheridos. Características: $3 \mathrm{~h}$ incubación y ZP procedente de ovocitos conservados en solución salina hipertónica (S.S) y vitrificados, 350x.

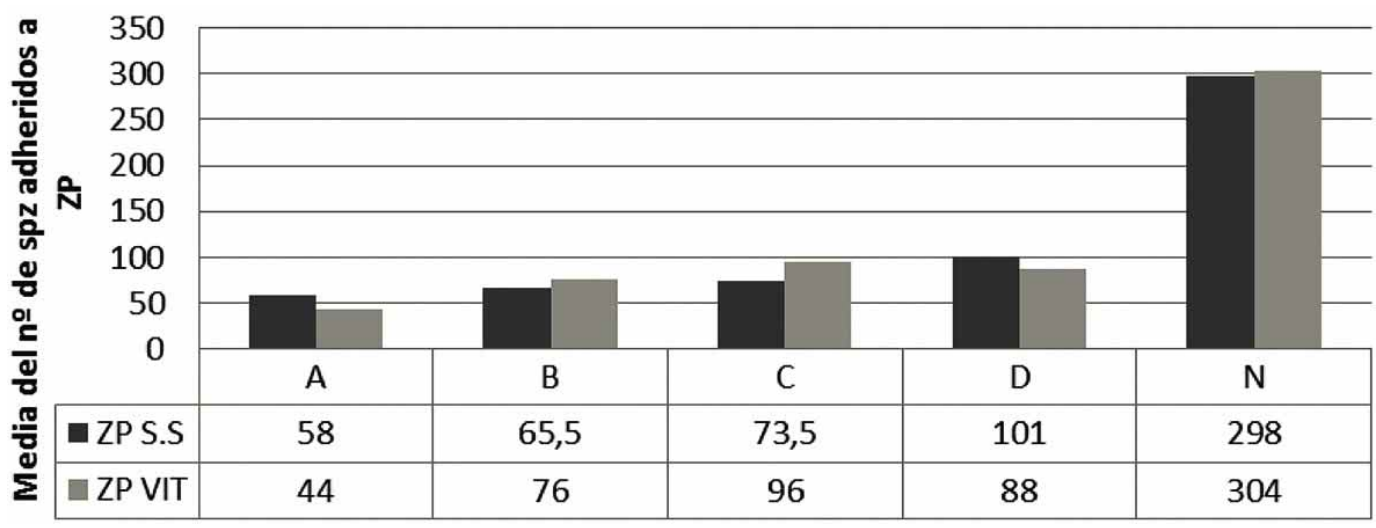

Fig. 4. Diagrama de barras con los resultados de los complejos analizados al MEB de la media del número de espermatozoides adheridos en cada cuadrante, comparando las ZP en solución salina (S.S) y las ZP vitrificadas (VIT). 


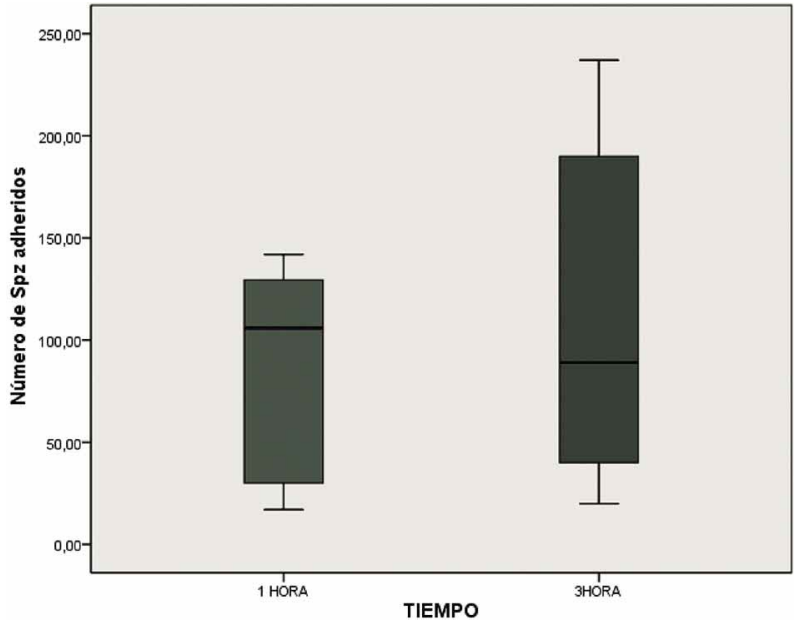

Fig. 5. Diagrama de cajas que muestra el número de espermatozoides adheridos a las ZP vitrificadas al cabo de 1 h y 3 h de incubación, teñidos con DAPI y observados con microscopia de fluorescencia. La línea gruesa marca la mediana.

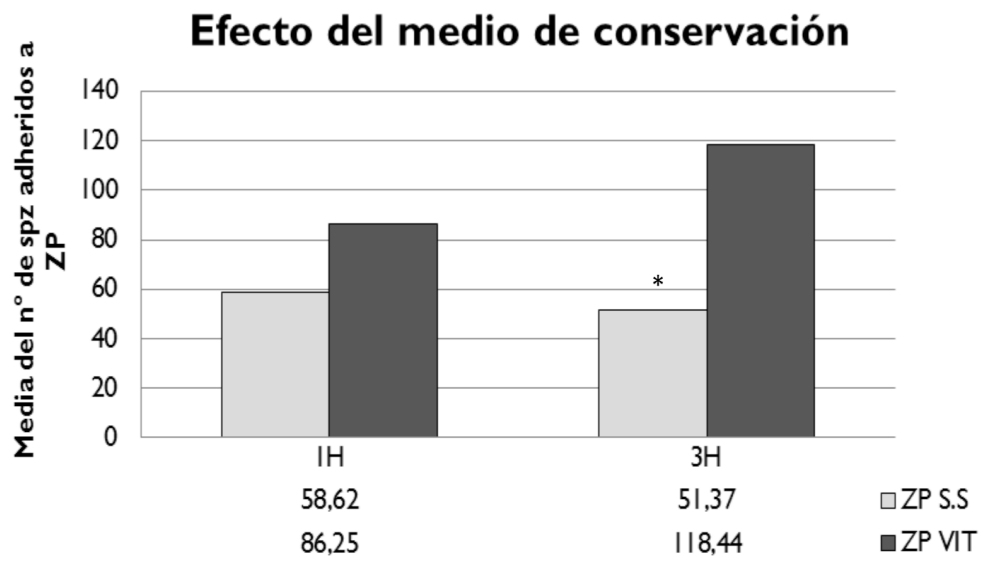

Fig. 6. Diagrama de barras donde se representa la media del número de espermatozoides adheridos a las ZP procedentes de las soluciones salinas y vitrificadas al cabo de 1 h y 3 h de incubación. *p<0,05.

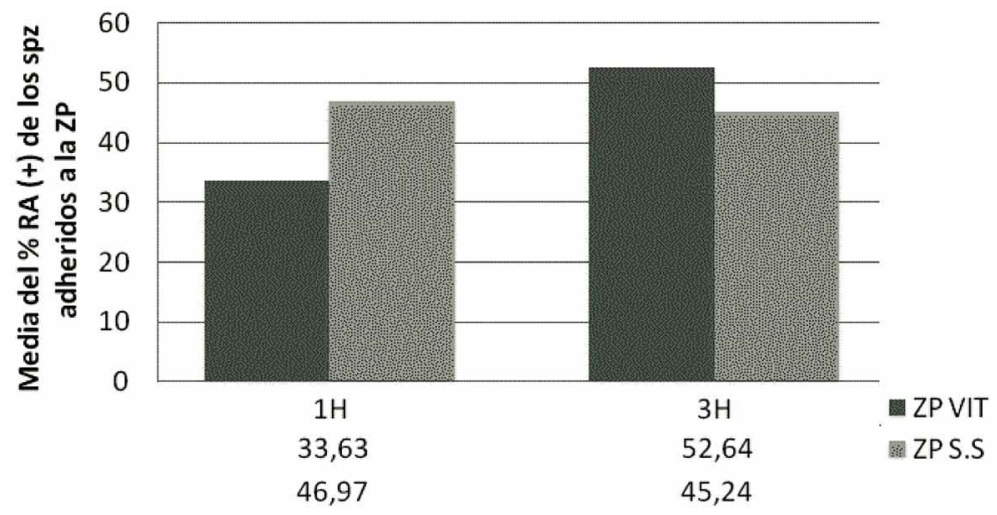

Fig. 7. Diagrama de barras donde se representa la media del porcentaje de espermatozoides reaccionados adheridos a las ZP procedentes de la solución salina y vitrificadas al cabo de 1 h y 3 h de incubación. b) Efecto del tiempo para las ZP en solución salina (S.S): No existen diferencias significativas, la media del número de espermatozoides para los distintos tiempos de incubación observados estuvo alrededor de 51-58.

c) Efecto del medio de conservación de las ZPs: Cuando el tiempo de incubación fue de 1 hora, no encontramos diferencias significativas entre las ZP vitrificadas y las ZP de solución salina. Sin embargo a las 3 horas de incubación observamos un aumento significativo en la media de espermatozoides que se unieron a las $\mathrm{ZP}$ vitrificadas (Fig. 6).

\section{Estado del acrosoma de los espermatozoides adheridos a} a) Efecto del tiempo para las ZP vitrificadas (VIT): No obtuvimos diferencias significativas en el porcentaje de espermatozoides reaccionados entre 1 hora y 3 horas de incubación. Destacar que a las 3 horas de incubación la media del porcentaje de espermatozoides reaccionados fue mayor (Fig. 7).

b) Efecto del tiempo para las ZP en solución salina (S.S): Cuando las ZP eran de solución salina la media del \% de espermatozoides reaccionados fue muy similar a 1 hora y las 3 horas de incubación.

c) Efecto del medio de conservación (ZP S:S vs ZP VIT): No hubo diferencias significativas en el estado acrosomal de los espermatozoides, al cabo de 1 hora y 3 horas de incubación, entre los dos grupos de estudio. Sí se observó cómo tras 1 hora de incubación, la media del porcentaje de espermatozoides reaccionados adheridos es ligeramente mayor para las ZP de solución salina. A las 3 horas ocurrió algo similar pero al contrario, siendo ligeramente mayor el de las ZP vitrificadas (Fig. 7).

d) Comparación entre ZP S:S, ZP VIT y grupos control: Tanto a 1 hora como a las 3 horas de incubación la media del porcentaje de espermatozoides reaccionados fue significativamente mayor en aquellas células que se habían adherido a las ZP de solución salina y las ZP vitrificadas, frente a los espermatozoides que no se unieron a las zonas y frente a aquellos que se capacitaron durante 1 y 3 horas. Estas diferencias fueron estadísticamente significativas tanto para 1 hora como para 3 horas de incubación (Fig. 8). 

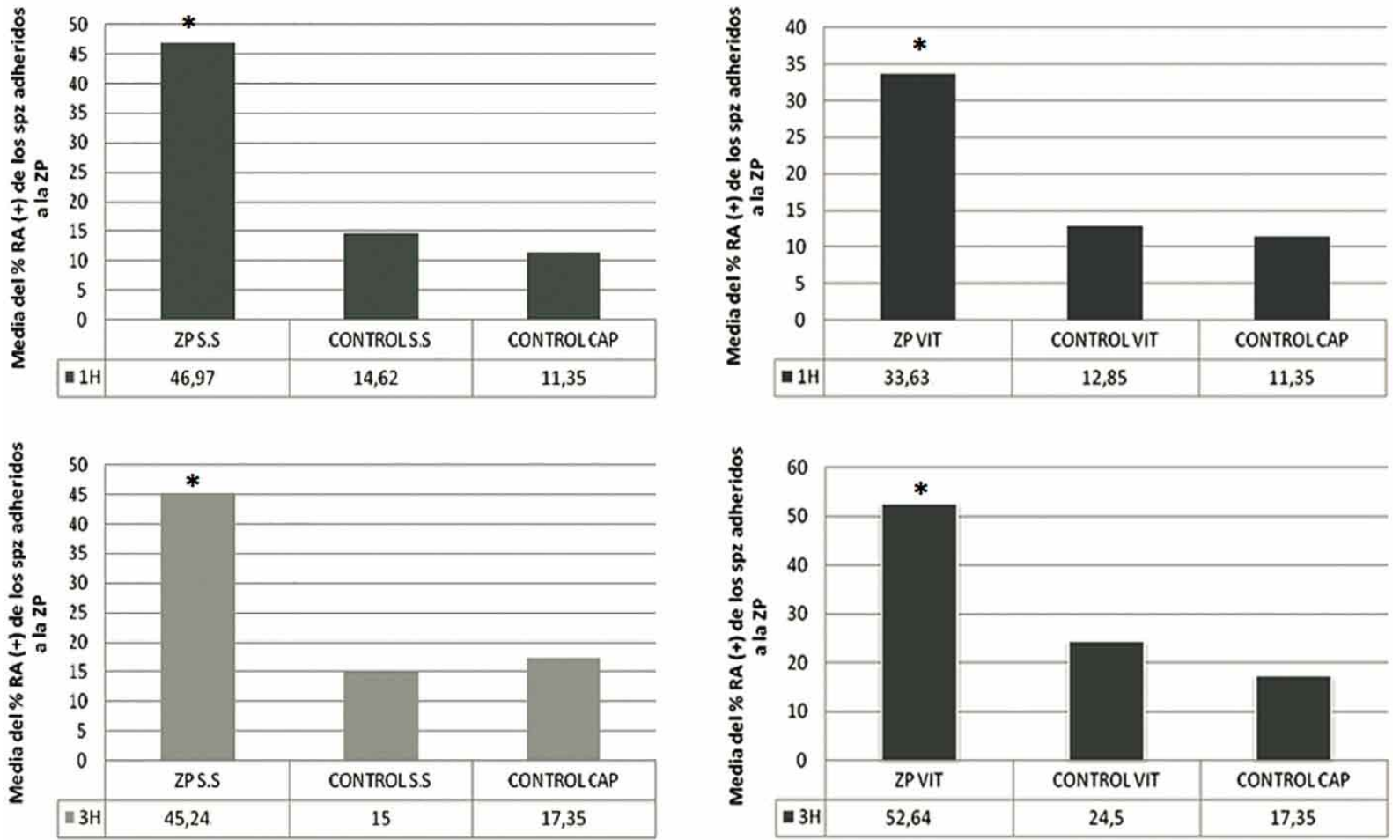

Fig. 8. Diagrama de barras donde se comparan la media del porcentaje de espermatozoides reaccionados en los diferentes grupos de estudio. ${ }^{*} \mathrm{p}<0,05$.

\section{DISCUSIÓN}

Existen diferencias en patrón de unión de los espermatozoides alrededor de la ZP, esto podría estar relacionado con la heterogeneidad molecular del oolema (Talbot et al., 2003), dichas diferencias en la composición de la membrana del ovocito proporcionan zonas donde la fusión de este con el espermatozoide es posible frente a otras regiones, por ejemplo la zona del oolema por debajo de la cual se encuentra el huso mitótico, será imposible la fusión de los gametos.

En cuanto a la reacción acrosómica, es sabido que la zona pelúcida induce la RA (Yanagimachi, 2011). Sin embargo nosotros hemos podido observar que no todos los espermatozoides que se adhieren a la zona son capaces de sufrir este proceso de exocitosis. Por lo cual, este test puede ser un buen Bioensayo para estudiar la capacidad fecundante del espermatozoide. Ya que la capacidad de unión de los espermatozoides a la zona puede correlacionarse con las alteraciones seminales.

Por otra parte, el método de vitrificación cerrado (S3) empleado en nuestro trabajo no altera el mecanismo de unión con los espermatozoides, ni la capacidad del glicocáliz del ovocito para inducir la reacción acrosómica. Por lo que po- dríamos decir que este procedimiento de vitrificación de ovocitos es adecuado y viable. En este sentido, pensamos que es necesario continuar con esta línea de trabajo y evaluar otros parámetros celulares del ovocito para ver si se alteran con el procedimiento de vitrificación empleado en nuestro trabajo.

Con respecto al tiempo de incubación, en nuestro estudio quisimos comprobar sí al aumentar el tiempo de incubación de los espermatozoides con las zonas pelúcidas también aumentaba la reacción acrosómica de los espermatozoides que se pueden adherir a la zona pelúcida. En vista de nuestros resultados, tanto la incubación de 1 hora como la de 3 horas es óptima para evaluar un parámetro fisiológico del espermatozoide tan importante como la reacción acrosómica. Nuestros resultados son similares a otros autores (Fazeli et al., 1997). Sin embargo hay otros autores que emplean tiempos muchos más largos (Oehninger et al., 1997).

Como hemos podido observar al analizar nuestros controles, los espermatozoides no adheridos a la zona no sufren reacción acrosómica, los porcentajes de espermatozoides reaccionados en este grupo están alrededor del $20 \%$, que es lo que se ha descrito como RA espontánea (Kawamoto et al.).

Por lo tanto podemos concluir que, el patrón de distribución de los espermatozoides adheridos a la zona es hetero- 
géneo tanto en ovocitos vitrificados como de solución salina, que el tiempo de incubación (1 y 3 horas) no afecta al número de espermatozoides adheridos a la zona ni a la reacción acrosómica tanto en zonas de ovocitos vitrificados como de solución salina. Y por último que la vitrificación cerrada (S3) no altera la capacidad de unión de los espermatozoides a la zona pelúcida, ni la capacidad de la zona pelúcida para inducir la reacción acrosómica.

VILELLA, I.; GARCÍA, E. M.; TEN, J.; BERNABEU, R.; SEGOVIA, H. Y.; GÓMEZ-TORRES, M. J. Effect of the vitrification of human oocytes on the binding capacity and acrosome status of human sperm. Int. J. Morphol., 33(3):835-841, 2015.

SUMMARY: To know the molecular aspects that occur in the process of human sperm binding to the human zona pellucida (ZP) is one of the great challenges of reproduction biology. Moreover knowing if the fertilization process may be affected by cryopreservation of female gametes is still another issue discussed in the literature. Based on this, the main objective of this study was to determine whether the oocyte vitrification may alter the interaction of sperm with the glycocalyx of ZP and show whether these oocytes lost the ability to induce the acrosome reaction in sperm. According to our results the oocyte closed vitrification method (S3) does not alter the ability of the sperm binding to the zona pellucida, and their ability to induce the acrosome reaction.

KEY WORDS: Hemizona test; Human oocytes; Acrosome reaction; Vitrification; Human sperm.

\section{REFERENCIAS BIBLIOGRÁFICAS}

Boiso, F. I. E. Efecto de la criopreservación sobre la estructura del huso meiótico de ovocitos humanos madurados in vitro. Tesis Doctoral. Barcelona, Universitat Autònoma de Barcelona, 2001.

Bray, C.; Son, J. H.; Kumar, P.; Harris, J. D. \& Meizel, S. A role for the human sperm glycine receptor/Cl(-) channel in the acrosome reaction initiated by recombinant ZP3. Biol. Reprod., 66(1):91-7, 2002.

Fazeli, A.; Hage, W. J.; Cheng, F. P.; Voorhout, W. F.; Marks, A.; Bevers, M. M. \& Colenbrander, B. Acrosome-intact boar spermatozoa initiate binding to the homologous zona pellucida in vitro. Biol. Reprod., 56(2):430-8, 1997.

Goldstein, I. J. \& Cortez, R. D. Isolation, physicochemical characterization and carbohydrate binding specificity of lectins. En: Liener, J. E.; Sharon, N. \& Goldstein, I. J. (Eds.). The Lectins. New York, New York Academic Press, 1986. pp.233-47.

Kawamoto, A.; Ohashi, K.; Kishikawa, H.; Zhu, L. Q.; Azuma, C. \& Murata, Y. Two-color fluorescence staining of lectin and anti-CD46 antibody to assess acrosomal status. Fertil. Steril., 71(3):497-501, 1999.

Lindsay, L. L. \& Hedrick, J. L. Proteolysis of Xenopus laevis egg envelope ZPA triggers envelope hardening. Biochem. Biophys. Res. Commun., 324(2):648-54, 2004.
Liu, D. Y. \& Baker, H. W. A simple method for assessment of the human acrosome reaction of spermatozoa bound to the zona pellucida: lack of relationship with ionophore A23187-induced acrosome reaction. Hum. Reprod., 11(3):551-7, 1996.

Martic, M.; Moses, E. K.; Adams, T. E.; Liu, D. Y.; Gook, D. A.; Garrett, C.; Dunlop, M. E. \& Baker, G. H. Recombinant human zona pellucida proteins ZP1, ZP2 and ZP3 co-expressed in a human cell line. Asian J. Androl., 6(1):3-13, 2004.

Ni, Y.; Li, K.; Xu, W.; Song, L.; Yao, K.; Zhang, X.; Huang, H.; Zhang, Y. \& Shi, Q. X. Acrosome reaction induced by recombinant human zona pellucida 3 peptides rhuZP3a22 approximately 176 and rhuZP3b177 approximately 348 and their mechanism. J. Androl., 28(3):381-8, 2007.

Nixon, B.; Lu, Q.; Wassler, M. J.; Foote, C. I.; Ensslin, M. A. \& Shur, B. D. Galactosyltransferase function during mammalian fertilization. Cells Tissues Organs, 168(1-2):46-57, 2001.

Oehninger, S.; Mahony, M.; Ozgür, K.; Kolm, P.; Kruger, T. \& Franken, D. Clinical significance of human sperm-zona pellucida binding. Fertil. Steril., 67(6):1121-7, 1997.

Rankin, T. \& Dean, J. The zona pellucida: using molecular genetics to study the mammalian egg coat. Rev. Reprod., 5(2):114-21, 2000.

Stachecki, J. S3 Vitrification System: a novel approach to blastocyst freezing. Fertil. Mag., 11:30-6, 2009.

Talbot, P.; Shur, B. D. \& Myles, D. G. Cell adhesion and fertilization: steps in oocyte transport, sperm-zona pellucida interactions, and sperm-egg fusion. Biol. Reprod., 68(1):1-9, 2003.

Yanagimachi, R. Mammalian fertilization. En: Knobil, E. \& Neil, J. D. (Eds.). The Physiology of Reproduction. 2nd ed. New York, Raven Press, 1994. pp.189-317.

Yanagimachi, R. Mammalian sperm acrosome reaction: where does it begin before fertilization? Biol. Reprod., 85(1):4-5, 2011.

Zhu, X. \& Naz, R. K. Comparison of ZP3 protein sequences among vertebrate species: to obtain a consensus sequence for immunocontraception. Front Biosci., 4:D212-5, 1999.

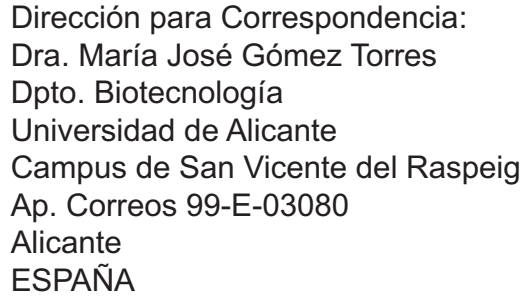

Email: mjose.gomez@ua.es

Recibido : 26-01-2015

Aceptado: 20-05-2015 